\title{
Current challenges and future opportunities of phage therapy
}

\author{
Diana P. Pires ${ }^{1}$, Ana Rita Costa ${ }^{2}$, Graça Pinto ${ }^{1}$, Luciana Meneses ${ }^{1}$ and \\ Joana Azeredo1,*
}

\author{
${ }^{1}$ CEB - Centre of Biological Engineering, University of Minho, Campus de Gualtar, 4710-057, Braga, Portugal \\ and ${ }^{2}$ Department of Bionanoscience, Kavli Institute of Nanoscience, Delft University of Technology, Van der \\ Maasweg 9, 2629 HZ, Delft, Netherlands \\ *Corresponding author: CEB - Centre of Biological Engineering, University of Minho, Campus de Gualtar, 4710-057, Braga, Portugal. Tel: +351253604414; \\ E-mail: jazeredo@deb.uminho.pt \\ One sentence summary: There is a remarkable potential of phage therapy for the control of antibiotic resistant infections within the One Health \\ approach, thus, the challenges currently faced and the potential solutions in development must be considered. \\ Editor: Grzegorz Wegrzyn
}

\begin{abstract}
Antibiotic resistance is a major public health challenge worldwide, whose implications for global health might be devastating if novel antibacterial strategies are not quickly developed. As natural predators of bacteria, (bacterio)phages may play an essential role in escaping such a dreadful future. The rising problem of antibiotic resistance has revived the interest in phage therapy and important developments have been achieved over the last years. But where do we stand today and what can we expect from phage therapy in the future? This is the question we set to answer in this review. Here, we scour the outcomes of human phage therapy clinical trials and case reports, and address the major barriers that stand in the way of using phages in clinical settings. We particularly address the potential of phage resistance to hinder phage therapy and discuss future avenues to explore the full capacity of phage therapy.
\end{abstract}

Keywords: clinical trials; phage resistance; phage engineering; phage cocktails; regulatory framework; One-Health

\section{INTRODUCTION}

The discovery of antibiotics in 1928 and their introduction in clinical practice has revolutionized the field of medicine. Since then and for decades, antibiotics were used to treat a wide range of severe infections, saving millions of lives (Davies and Davies 2010). However, nobody predicted what was about to come a few decades later. As a consequence of antibiotic overuse and misuse, bacteria managed to develop multiple antibiotic resistance mechanisms, and the golden age of antibiotics has come to an end (Davies and Davies 2010; Malik and Bhattacharyya 2019). We are currently facing a post-antibiotic era, in which common infections or minor injuries can become fatal (WHO 2014). Recent reports state that more than 2.8 million antibioticresistant infections occur each year in the United States and that more than 35000 people die as a result (Centers for Disease Control 2019). In Europe, approximately 33000 people die every year from antibiotic-resistant infections (Cassini et al. 2019). If no action is taken, the World Health Organization estimates that drug-resistant infections could kill about 10 million people per year by 2050. The search and development of new and effective antibacterial compounds is urgently required to avoid such a threatening future, and (bacterio)phages might play a major role in tackling this global crisis.

Phages are bacterial viruses and the most abundant entities on Earth (Clokie et al. 2011; Fernández et al. 2019). While the use of phages in human therapy begun soon after their discovery by Frederick Twort and Félix d'Hérelle over a century ago, their application in clinical practice in Western countries was quickly overshadowed by the introduction of antibiotics 
(Chanishvili 2012; Gordillo Altamirano and Barr 2019). In places such as Georgia and Poland, phage therapy remained active until today, mostly via two major phage therapy centres: the Eliava Institute of Bacteriophages, Microbiology and Virology (Tblilisi, Georgia) and the Ludwik Hirszfeld Institute of Immunology and Experimental Therapy (Wroclaw, Poland) (Rohde, Wittmann and Kutter 2018). Many patients with antibiotic-resistant infections are traveling from multiple places in the world to these centres to receive individualized phage treatments as a last hope (Rohde, Wittmann and Kutter 2018). Despite all the success cases of patients treated with phages documented to date, the introduction of phage therapy in Western countries still faces major obstacles, especially regulatory issues (Fauconnier 2019). Now, efforts to make phage therapy widely available are ongoing and a number of clinical trials are being conducted in Europe and in the United States (Sybesma et al. 2018; Fauconnier 2019). In this review, we will first discuss the current state of phage therapy in the Western world and then address the major challenges faced by phage therapy and the future opportunities in this field.

\section{THE CURRENT STATUS OF PHAGE THERAPY}

The clinical use of phages to treat a wide range of infections begun in the early 1920s. However, inconsistent results reported about phage trials during the 1930s as well as the lack of controls and inappropriate characterization, production and purification of phage preparations raised important concerns about the safety and efficacy of this therapy (Gordillo Altamirano and Barr 2019). As such, phage therapy remained active only in a few countries of Eastern Europe, where studies have provided substantial evidence of the efficacy of phages to treat certain infections with no adverse effects reported (Sulakvelidze, Alavidze and Morris 2001; McCallin and Brüssow 2017). Still, the lack of confirmation in line with evidence-based medicine, i.e. clinical trials, fuels the reluctance of regulatory agencies and clinicians from Western countries on the use of phage therapy (Sybesma et al. 2018). To establish phage therapy as a feasible alternative to antibiotics, clear efficacy data from randomized controlled clinical trials is required (McCallin et al. 2019). To tackle this situation, an increasing number of clinical trials have been carried out over the last years but only a few are currently completed (Furfaro, Payne and Chang 2018; Rohde, Wittmann and Kutter 2018; Sybesma et al. 2018).

In 2009, Wright et al. reported a randomized, double-blind, placebo-controlled phase I/II clinical trial approved by both UK Medicines and Healthcare products Regulatory Agency (MHRA) and the Central Office for Research Ethics Committees (COREC) (Wright et al. 2009). This trial was carried out on 24 patients with chronic otitis to assess the efficacy and safety of a phage preparation composed of six phages for the treatment of otitis caused by antibiotic-resistant Pseudomonas aeruginosa. By the end of the trial (day 42), all the clinical indicators (e.g. inflammation, ulceration, discharge type and quantity, and odour) improved in patients treated with phages, but only three of the 12 patients receiving phage treatment were apparently cured. Importantly, no serious adverse effects were reported (Wright et al. 2009). Also in 2009, Rhoads and colleagues reported another randomized, double-blind controlled study that addressed the safety (and not efficacy) of a phage cocktail targeting P. aeruginosa, Staphylococcus aureus and Escherichia coli for the treatment of venous leg ulcers (VLU) (Rhoads et al. 2009). This first phage therapy trial in the United States involved 42 patients with VLU. Patients were topically treated with either phage cocktail or saline solution (control) for 12 weeks with a follow-up period of up to 24 weeks.
No adverse effects were associated with phage treatment, but no significant differences were found on the rate and frequency of healing between phage-treated and control groups. This is not surprising as the phages were not tested for infectivity on the bacteria causing the VLU. According to the authors, the efficacy of the phage preparation should be evaluated in a phase II efficacy trial with a larger sample and with wounds infected with bacteria susceptible to the phage cocktail (Rhoads et al. 2009).

The largest clinical trial on phage therapy conducted in Europe and performed under both good manufacturing practices (GMP) and good clinical practices (GCP) was the PhagoBurn trial, launched in 2013. In this multicentre randomized controlled phase I/II clinical trial, 27 patients suffering from burn wound infections were recruited from hospitals located in France and Belgium to be randomly treated with phage therapy (a cocktail of 12 lytic phages) or standard care (1\% sulfadiazine silver emulsion cream) to compare the efficacy and tolerability of both treatments in patients with wounds infected by P. aeruginosa (Jault et al. 2019). Both treatments were topically administered for seven days with a 14 days follow-up period. Overall, the phage cocktail was able to decrease bacterial burden in burn wounds but the progress was slower than in the control group (standard treatment). On the positive side, no adverse effects were found in the phage-treated group. The limited efficacy of the phage cocktail was reported to be caused by a significantly drop of the phage titre after GMP manufacturing, leading the participants to receive a much lower concentration of phages than initially estimated. More importantly, the susceptibility of wound bacteria to the phage cocktail was not assessed prior to treatment. In those patients in which phage treatment failed, bacteria were later found to be resistant to low phage doses (Jault et al. 2019).

Nestlé (Switzerland) also performed a phase I/II trial in collaboration with the Dhaka Hospital of the International Centre for Diarrheal Disease Research, Bangladesh (Sarker et al. 2016). This randomized double-blind, placebo-controlled trial was conducted between 2009 and 2011 to assess the safety and efficacy of oral administration of a T4-like phage cocktail or a placebo, in children hospitalized with acute bacterial diarrhea. Although the oral coliphages could reach the intestine, no phage replication was observed, and the treatment had no beneficial effects. At the time, the authors attributed the failure to improve diarrheal outcome to the low host range coverage of the phage cocktail (i.e. some strains were not infected) and also the need of higher oral phage doses (Sarker et al. 2016). Indeed, oral application of phages without any protection (e.g. encapsulation of the phages or neutralization of the stomach acid) prior to administration reduces the phage numbers reaching the intestine to levels that might be insufficient for a visible therapeutic effect. Later, it was also found that E. coli was not the main cause of acute bacterial diarrhea, and therefore even an efficient phage treatment of E. coli would not result in improved diarrheal outcome (Satter et al. 2017; Nelson et al. 2018). This Nestlé trial and the clinical trial developed by Rhoads et al. highlight the importance of identifying the etiologic agent(s) causing infection and of checking for phage susceptibility prior to treatment. Therefore, phage therapy clinical trials must be carefully designed to avoid potential problems that might impair the outcome of the treatment. Recently, Ooi et al. reported a clinical trial aiming to assess the safety, tolerability and preliminary efficacy of a phage cocktail composed of three lytic phages, applied intranasally in patients with recalcitrant chronic rhinosinusitis (CRS) caused by S. aureus (Ooi et al. 2019). In this open label, phase I clinical trial, only patients carrying a clinical isolate sensitive 
to the phage cocktail were considered. Overall, the twice-daily intranasal irrigation of phages was safe and well tolerated by the nine patients through the 14 days treatment, with no serious adverse events reported. While the preliminary efficacy observations seem promising (two of the nine patients had eradication of infection), the authors highlighted the need for a randomized clinical trial to determine the optimal dose regimen and demonstrate the efficacy of the phage cocktail (Ooi et al. 2019). The high safety of phage therapy has already been reported in multiple patients from the phage therapy unit in Poland (Międzybrodzki et al. 2012; Rogóż et al. 2019).

While most clinical trials have failed to provide unequivocal evidence of the efficacy of phage therapy, the number of case studies in which phage therapy was successfully used to treat life-threatening infections is increasing (Table 1) (Sybesma et al. 2018; McCallin et al. 2019). Some of these successful cases have reached the media (Dedrick et al. 2019; Strathdee, Patterson and Barker 2019), fostering the interest of the global community in this therapy. One of these newsworthy cases concerned a 68-year-old man who suffered from necrotizing pancreatitis complicated by an Acinetobacter baumannii multidrug-resistant infection (Schooley et al. 2017). Despite multiple rounds of antibiotic treatments, the patient condition rapidly deteriorated over time. Therefore, the A. baumannii strain isolated from the patient was used to screen for phages in two different laboratories, which made possible to compose phage cocktails tailored for the patient. Phage administration (via catheters into the abdominal cavity and also intravenously) rapidly reverted the clinical condition of the patient by clearing the infection (Schooley et al. 2017). Phage therapy documentaries have also been broadcasted on television in many countries (Djebara et al. 2019). As a consequence, the Queen Astrid military hospital in Brussels, Belgium, has experienced a huge increase in external phage therapy requests since 2017 (Djebara et al. 2019). The majority of these requests were initiated by the patients themselves and came mostly from the Netherlands followed by Belgium and France. Among the 260 phage therapy requests received by the hospital between 2013 and 2018, only 15 patients, who were infected with bacterial pathogens susceptible to the available phages, received treatment but these data were not yet reported (Djebara et al. 2019).

The rising interest in phage therapy by patients and physicians and the consequent increase of requests for phages from all over the world highlights a growing need for the establishment of phage banks with well characterized phages that could facilitate access by the international community. Some phage banks have already been established, such as the Félix d'Hérelle Reference Center for Bacterial Viruses at the University of Laval (Québec, Canada), the Leibniz Institute DSMZ German Collection of Microorganisms and Cell Cultures (Braunschweig, Germany), the Bacteriophage Bank of Korea (Yongin, South Korea), the American Type Culture Collection (ATCC) Bacteriophage Collection (Virginia, USA), the National Collection of Types Cultures (NCTC) Bacteriophage Collection (Salisbury, UK) (McCallin et al. 2019; Sacher 2019), and the Fagenbank (Delft, the Netherlands). It is important that phage researchers feed these global phage banks to have a larger coverage of (pathogenic) bacterial species.

\section{CURRENT CHALLENGES IN PHAGE THERAPY}

Quality and safety requirements

The success of phage therapy is highly dependent on the safety of phage preparations, which raises manufacturing and formulation challenges (Fig. 1A). For broad medical applications, phages would need to be produced in large scale under Good Manufacturing Practices (GMP) approved by regulatory agencies (Regulski, Champion-Arnaud and Gabard 2018). Although the production of phages for therapy must comply with the strict regulations that are usually applied for pharmaceutical products to ensure the high quality standards appropriate for their intended use, no clear guidelines were yet developed specifically for phage manufacturing (Mutti and Corsini 2019). To address this issue, a group of phage researchers have set some quality and safety requirements for sustainable phage therapy products (Pirnay et al. 2015). One of the requirements is to avoid phages encoding for lysogeny, virulence factors or antibiotic resistance. However, this might limit the use of phage therapy in some fastidious bacteria for which no strictly virulent phages have been found so far, such as Clostridium difficile (Hargreaves and Clokie 2014).The presence of impurities such as endotoxins in phage preparations should also be avoided or be below a threshold (Pirnay et al. 2015). Several purification methods have been developed and optimized to remove these toxic elements from phage preparations (Hietala et al. 2019), but none has reached optimal results so far.

It is important to note that as phages are biological entities, the development of robust manufacturing processes in compliance with GMP is also essential to avoid variability among phage preparations (García et al. 2019; Mutti and Corsini 2019). Another important aspect is the quality control of phage stock preparations. This should be regularly assessed by checking for their stability (shelf life), sterility and cytotoxicity, as well as by performing periodic $\mathrm{pH}$ measurements (Merabishvili et al. 2009; Pirnay et al. 2015). Although recent progress in phage manufacturing has revitalized phage therapy in Western countries, there is still a long way to go before a general approval is reached for the use of phage therapy (Regulski, Champion-Arnaud and Gabard 2018).

\section{Stability of phage preparations}

The stability of phage preparations is a key requirement for successful treatment and also for the regulation of phages as pharmaceuticals. A potential phage candidate for therapy should have a good shelf life, i.e. it should be stored in a formulation that ensures activity without significant drop in phage titre during processing and long-term storage (Fig. 1B), as such decrease might compromise the outcome of the treatment (Malik et al. 2017; Merabishvili, Pirnay and De Vos 2018; Jault et al. 2019). Several strategies have been developed and optimized to improve phage stability and the most common include spray-drying, freeze drying, extrusion dripping methods, emulsion and polymerisation techniques (Malik et al. 2017). However, phage stability in different formulations (e.g. liquids, gels, powders) is highly variable, especially among different phage types (Leung et al. 2017; Gonzalez-Menendez et al. 2018; Merabishvili, Pirnay and De Vos 2018). An alternative strategy to improve the storage shelf life of phages is their encapsulation on different matrices such as liposomes, alginate, cellulose or other polymers (Malik et al. 2017; Cortés et al. 2018). Phage encapsulation strategies are important not only to achieve longer shelf life but also for therapeutic purposes. Because treatment efficacy highly depends on phage concentration at the site of infection, protecting phages from the harsh conditions found in the human body is vital to avoid phage inactivation during treatment due to e.g. low $\mathrm{pH}$ or clearance mechanisms associated with the immune system (Malik et al. 2017; Dacbrowska 2019). In fact, the immune system plays a crucial role in phage clearance or inactivation from animal and human bodies. Most studies on the immune 


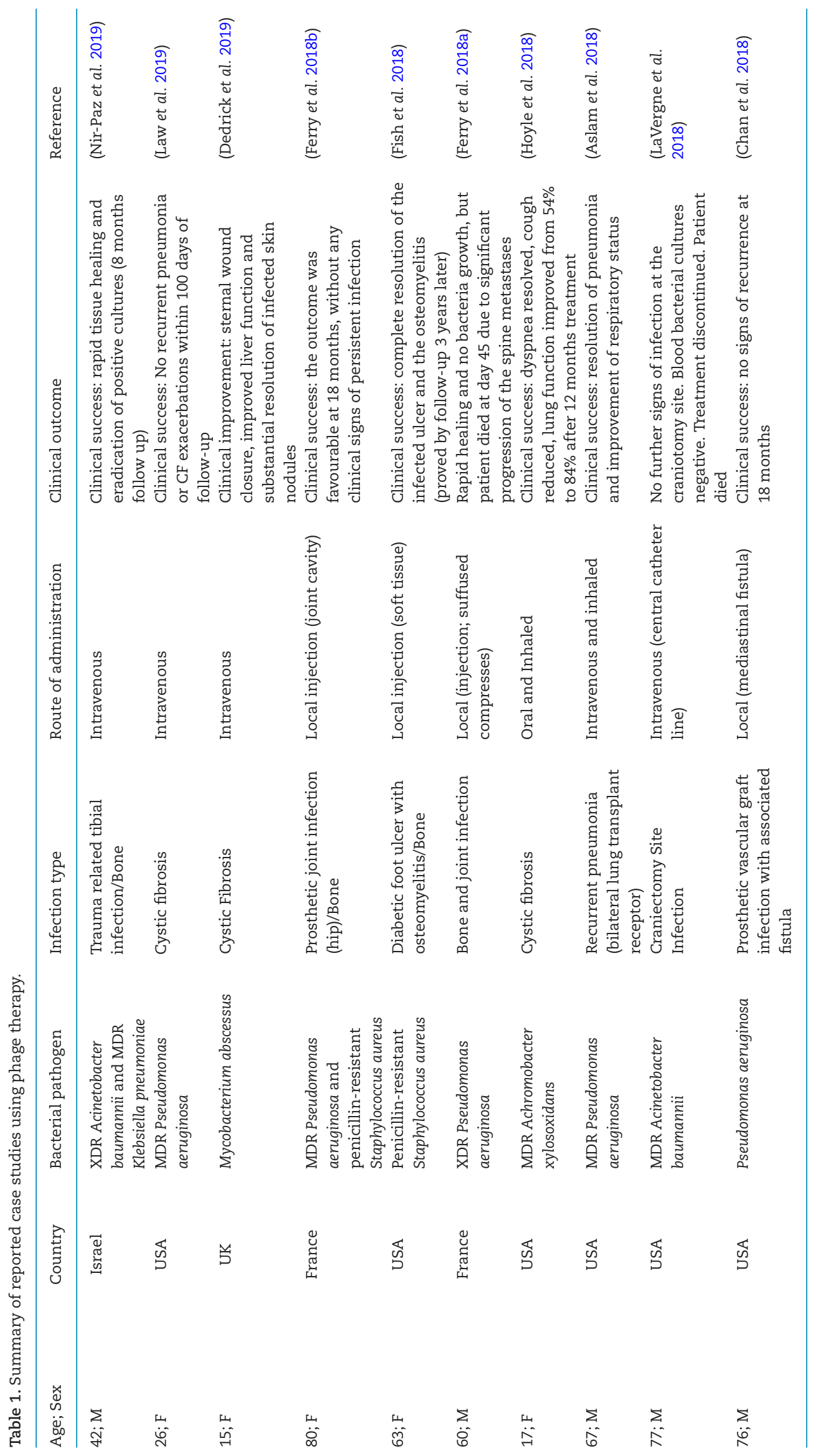




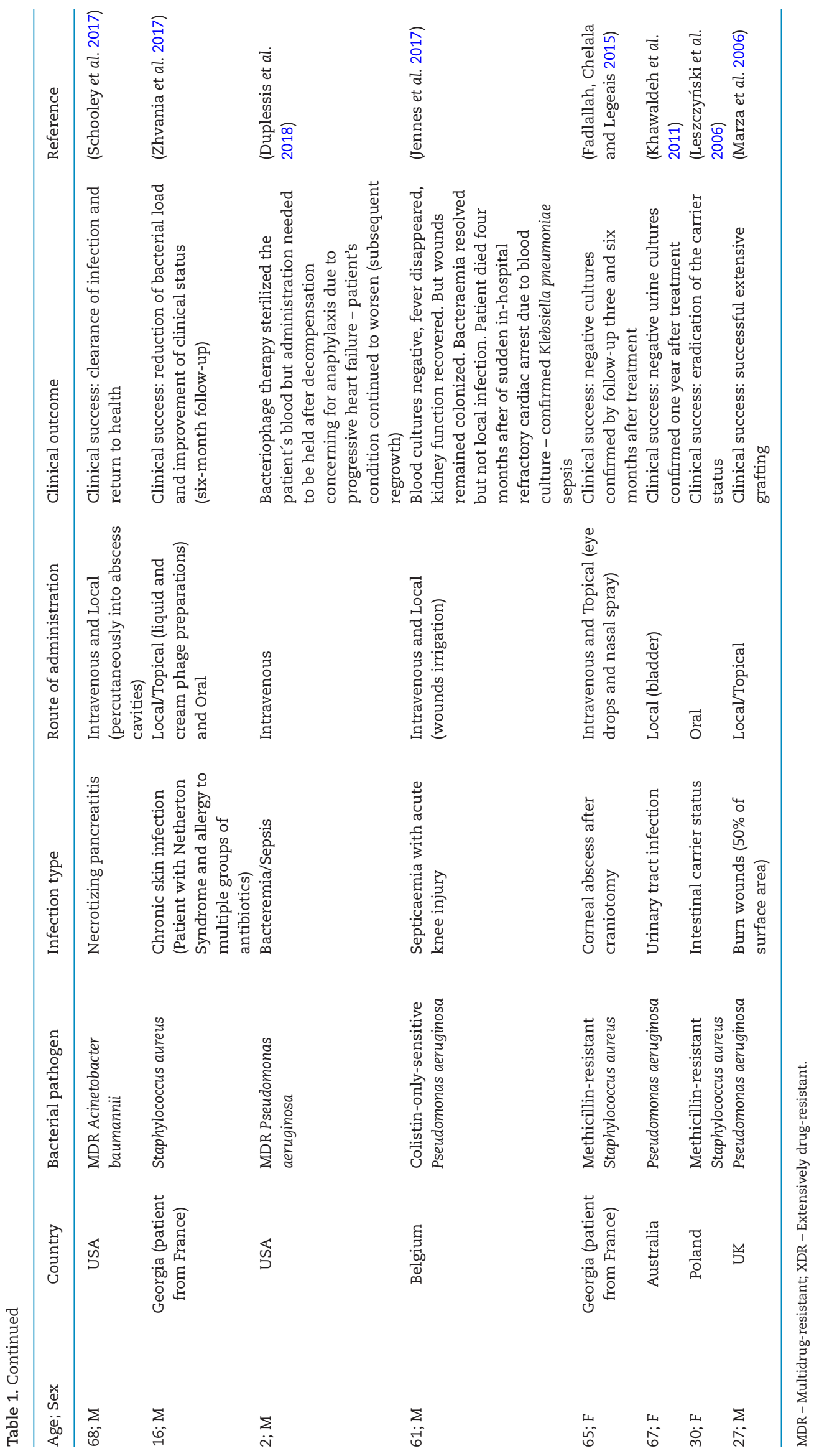


(A)

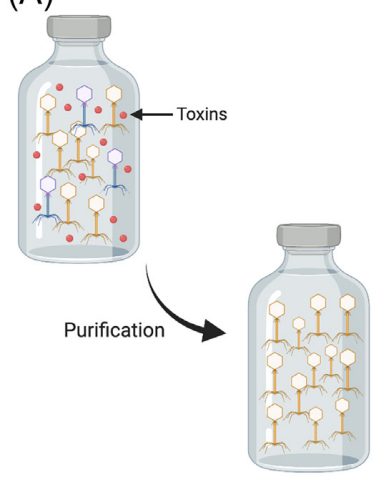

(D)
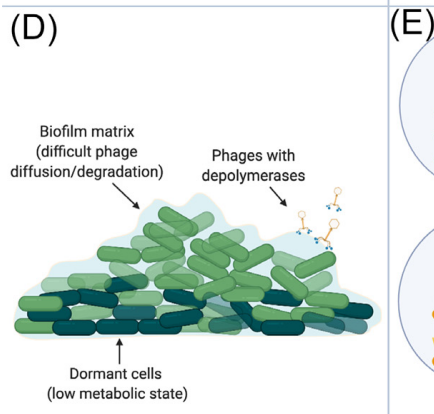

(E)
(B)
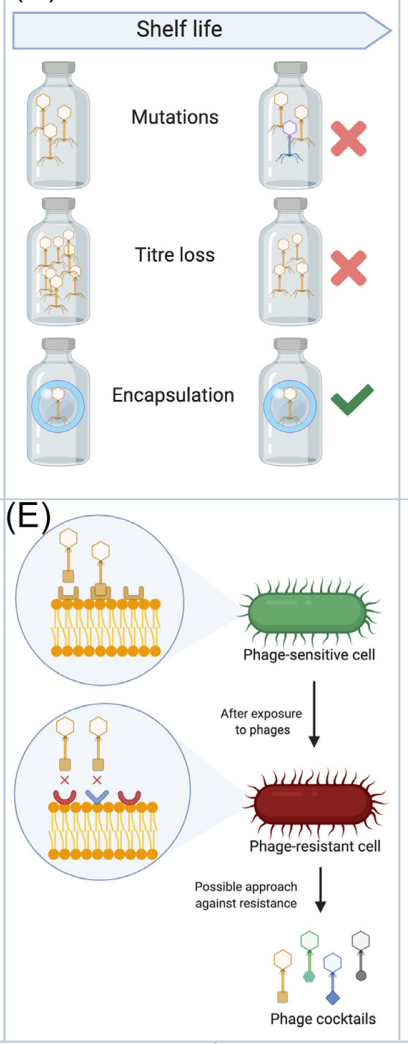

(C)

(C)

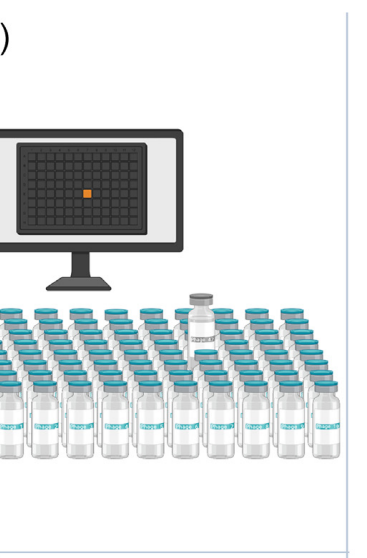

$(\mathrm{F})$

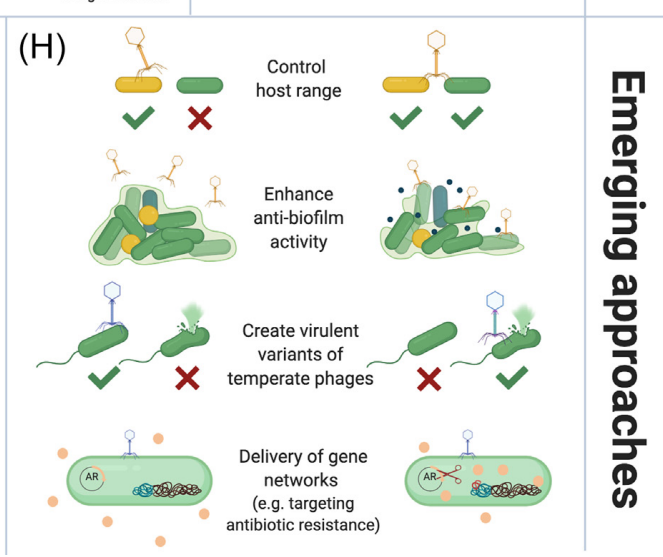

Figure 1. Current challenges and emerging approaches in phage therapy. Phage therapy currently faces challenges such as (A), conforming to the current quality and safety requirements, (B), guaranteeing stability of phage preparations for long periods of time, (C), developing a high-throughput assay for phage screening, (D), overcoming the limited activity of phages in biofilms, (E), controlling and overcoming the development of bacterial resistance to phages and (F), establishing a regulatory framework more adequate to phage products. Simultaneously, different approaches are being developed to improve phage therapy, which include (G), the use of combined approaches such as the use of both phages and antibiotics or $(\mathrm{H})$, the exploitation of synthetic biology tools to engineer phages with improved features. This figure was created with BioRender.com and exported under a paid subscription.

response to phages have focused on the development of phagespecific antibodies (adaptive immunity). These have been shown in many cases to decrease the circulation of phages, but other studies have reported no antibody formation or no effect of the formed antibodies on the ability of phages to clear the infection (Dabrowska 2019). In vitro and in vivo studies have demonstrated the ability of encapsulated phages to persist for longer periods at low $\mathrm{pH}$, enhancing the efficacy of oral administration in animal models (Yongsheng et al. 2008; Ma et al. 2012; Colom et al. 2017; Otero et al. 2019; Vinner et al. 2019). More studies are required to understand protection given by encapsulated strategies against immune clearance of phages. The protection of phages is also important for certain combined therapies that can inactivate phages when applied together and impair the outcome of the treatment. As an example, burn wound care products and their active ingredients usually exhibit high acidity that can negatively affect the activity of phages in wounds (Merabishvili et al. 2017).

Another issue of phage stability is the occurrence of spontaneous mutations in phage stocks stored for long periods or accumulated during phage production and manufacturing, which can impair viral fitness (Drake 1966; Botka et al. 2019). Although difficult, it would be helpful to predict phage evolution during production to set up a manufacturing process that 
would minimize the mutation rates in phage genomes (García et al. 2019).

\section{Fast phage screening methods}

Due to the high specificity of phage activity, finding a phage that targets a particular strain often requires the screening of large phage collections (Fig. 1C). The most traditional method to detect phage activity against a strain is the double layer agar (DLA) method, in which different phages are spotted on top of a lawn of the bacteria of interest (Cornax et al. 1990; Kropinski et al. 2009). Depending on the growth rate of the particular strain to target, results may take up to $48 \mathrm{~h}$ to show and therefore the DLA method is not convenient in a therapeutic context where fast diagnosis is crucial. High-throughput and fast-screening methods are desirable to rapidly identify phage(s) able to efficiently infect the target strain(s).

Multiple methods have been developed for the detection and quantification of phages, via direct or indirect measurements, but few seem to have application in a clinical setting. For example, real-time PCR (qPCR) methodologies (Del Rio et al. 2008; Ly-Chatain et al. 2011) have been developed for fast and sensitive detection of phages and for the identification of infection via detection of increasing phage concentrations. But qPCR methods require a set of primers and optimized conditions for (almost) every phage, which is neither high-throughput nor feasible when testing large (and fast expanding) phage collections against a target strain.

Flow cytometry has also been used to reveal phage infection via detection of cells with low-density cell walls (Michelsen et al. 2007). Low-density cell walls have been observed as a consequence of phage infection in Lactococcus lactis. The method allows for fast and early detection of phage infection, but is low-throughput and most likely not universal for all bacterial species and/or phages. Some other works have detected phage propagation indirectly via measuring enzyme release from bacterial cells due to phage-induced cell lysis. Intracellular enzymes such as adenylate kinase and adenosine 5'-triphosphate (ATP) or $\beta$-galactosidase have been tested as measurements of infection by E. coli phages (Stanek and Falkinham 2001; Guzmán Luna et al. 2009). Enzyme release is detected by the generation of a bioluminescence or colour signal after cleavage of a specific substrate. These assays are highly sensitive, generating a detectable signal in a short time $(\approx 3 \mathrm{~h})$ even when starting with a low phage amount. Such methods are compatible with highthroughput and, in theory, work with any phage but may need to be optimized (e.g. enzyme/substrate selected) for each bacterial species.

The aptitude of surface plasmon resonance (SPR) techniques to measure and quantify molecules bound to surfaces was explored to study the interaction between phages and bacterial host (García-Aljaro et al. 2008). For this method, bacteria are immobilized on gold sensor chips using avidin-biotin, and binding of phages to the bacteria and consequent bacterial lysis can be detected and measured with high sensitivity in just $2 \mathrm{~h}$. As it is, however, the method is not compatible with high-throughput screening as only a strain-phage pair can be tested simultaneously. A microfluidics adaptation of the method, in which multiple channels are created to test multiple phages simultaneously, could provide an interesting solution.

Cell respiration can also be used as a reporter for cellular growth and, consequently, for phage infection. Using this principle, Henry and colleagues developed the OmniLog ${ }^{\mathrm{TM}}$ system, in which cell respiration is measured using redox chemistry via reduction of a tetrazolium dye that produces a colour change measured in microtiter plates (Henry et al. 2012). Successful phage infection is detected by a reduction in colour due to reduced bacterial growth and respiration. Such method is simple and high-throughput, but might be limited to aerobic bacteria.

A simple approach was also recently suggested based on the analysis of optical density kinetics in bacterial cultures for the detection and quantification of phages (Rajnovic, Muñoz-Berbel and Mas 2019). This method detects phages at low amounts with a response time of $3.5 \mathrm{~h}$, and is susceptible of miniaturization and automation for high-throughput applications that can be implemented in routine analysis. A possible drawback is that it relies solely on a change in optical density of the bacterial culture, which is not always observable for lytic phages.

In the future, a simple and fast high-throughput method for phage screening should be established and implemented in clinical settings and in phage banks, if phage therapy is to be widely used as a treatment option.

\section{Efficacy of phages against biofilms}

In nature and in the human body, bacteria are most often found in the form of a biofilm. A biofilm can be defined as a population of bacteria attached to a surface and embedded within a self-produced matrix (Hobley et al. 2015). In biofilms, bacterial cells closely collaborate as a strategy for survival and persistence in harsh environments (Costerton et al. 1995), e.g. providing increased tolerance to antibiotics (Costerton, Stewart and Greenberg 1999; Stewart and Costerton 2001). Phage-bacteria interactions have been mostly studied in planktonic cultures, but these interactions have been shown quite distinct for bacteria in a biofilm form. Studies have revealed the therapeutic potential of phages to control both mono-species (Curtin and Donlan 2006; Fu et al. 2010; Alves et al. 2015; Melo et al. 2016) and dual-species biofilms (Sillankorva, Neubauer and Azeredo 2010; Lehman and Donlan 2015; Gutiérrez et al. 2015b), but multiple works have also unveiled the impressive complexity and diversity of phage-biofilm interactions.

Within biofilms, bacteria are protected by a matrix composed mainly of polysaccharides, lipids, extracellular DNA, and proteins (Hobley et al. 2015; Seviour et al. 2019). The matrix is a major factor influencing the ability of a phage to successfully disturb a biofilm (Darch et al. 2017), via several suggested mechanisms. The matrix can adsorb phages (Bull et al. 2018) or simply form a physical barrier for phage diffusion (González et al. 2018; Dunsing et al. 2019), preventing phages from reaching and infecting the living cells within the biofilm (Fig. 1D). Phages have, however, developed strategies to counteract the limiting effects of the matrix on their activity (Pires et al. 2017a). Many phages encode polysaccharide-degrading enzymes known as depolymerases, which are used to degrade capsular polysaccharides of bacteria and thereby give the phage access to its receptor on the bacterial cell surface. Some depolymerases can also degrade exopolysaccharides of the biofilm matrix and improve access of the phages to the bacterial cells (Harper et al. 2014; Gutiérrez et al. 2015a). The activity of depolymerases tends to be very specific for a certain polysaccharide type, and the use of a phage cocktail encoding for different depolymerases may represent a good treatment solution, and even enhance the activity of other nondepolymerase producing phages (Schmerer, Molineux and Bull 2014).

The spatial organization of the biofilm is also a determinant factor for phage infection. To form a biofilm, cells organize so 
that localized niches are created with distinct nutrient availability and consequently with bacteria of distinct motility, metabolic state, and gene expression, all of which affect the capacity of phages to infect biofilm cells. The diffusion of the phage through the biofilm is limited by the close proximity of the cells, which may cause multiple phages to infect the same host cell and decrease the number of progeny phages the cell generates (Taylor, Penington and Weitz 2017). Still, it is also possible that local infection of a biofilm leads to a significant disruption of the biofilm structure, ultimately leading to its dispersal and easier removal.

The establishment of nutrient gradients often leads to the generation of dormant persister cells in the deeper layers of the biofilm, where nutrient resources are scarce. Phages infecting these metabolically inactive cells are expected to be unable to propagate as they, in principle, cannot use the (inactive) replication machinery of the cell (Loś et al. 2007; Pearl et al. 2008). However, a Staphylococcus infecting phage was recently shown capable of propagating in dormant staphylococcal cells, a feature expected to be present in other phages yet to discover (Melo et al. 2018; Tkhilaishvili et al. 2018). Additionally, phages can remain within the persister cells until they exit the state of dormancy, being then able to propagate as normal (Pearl et al. 2008).

Gene expression in biofilms is frequently controlled by quorum sensing, which involves the use of extracellular signal molecules that sense population density to coordinate gene expression (Ng and Bassler 2009). Quorum sensing can be used by bacteria to respond to phage infections, for example by regulating expression of CRISPR-Cas systems (Patterson et al. 2016; Høyland-Kroghsbo et al. 2017) and of phage receptors (HøylandKroghsbo, Maerkedahl and Svenningsen 2013; Tan, Svenningsen and Middelboe 2015), and also by regulating the production of biofilm matrix (Parsek and Greenberg 2005). Some phages have developed strategies to exploit the bacterial quorum sensing system to guide their lysis-lysogeny decision either by encoding receptors for the bacterial quorum sensing molecules (Silpe and Bassler 2019) or by expressing their own extracellular signalling molecules once inside the bacteria (Erez et al. 2017). By sensing the bacterial population, phages can sense a favourable or unfavourable environment for lytic development.

Biofilms are also known to release outer membrane vesicles (OMVs) in high number. These OMVs may contain outer membrane proteins used as receptors by some phages, and therefore work as a decoy for phage infection, protecting biofilm cells from phages (Manning and Kuehn 2011; Reyes-Robles et al. 2018). Nevertheless, phages that use receptors other than outer membrane proteins (e.g. lipopolysaccharides) are not affected by such strategy.

Dispersion of bacteria from a biofilm for colonization of a new niche is an important step of the biofilm life cycle. Phages may be interesting solutions to control the spreading step of a biofilm infection, as some phages unable to eradicate a biofilm can still inhibit dispersal of migrating bacteria and the establishment of new colonies (Darch et al. 2017).

Most in vitro work in biofilms has been performed using single strains. Natural biofilms, however, are often multi-strain or multi-species, which significantly affects the biofilm spatial organization and the interaction with phages. The specific outcome of phage infection in a multi-species biofilm seems to strongly depend on the bacterial species composing the biofilm (e.g. whether they establish synergist or antagonist interactions). Some studies have reported the ability of phages to target the susceptible host in the biofilm independently of the presence of a non-susceptible strain (Harcombe and Bull 2005; Kay et al. 2011; Gutiérrez et al. 2015a). A few works, however, suggest the presence of insensitive strains to provide spatial structureassociated protection to the sensitive bacteria against phage infection, thereby reducing the efficacy of phage treatment (Tait, Skillman and Sutherland 2002; Testa et al. 2019). Broad host range phages (Kim et al. 2012) as well as phages carrying depolymerases (Pei and Lamas-Samanamud 2014) may be particularly efficient against multispecies biofilms. In the latter case, the diversity and heterogeneous distribution of exopolysaccharides on a multi-species biofilm may limit depolymerase activity.

The complexity of phage-biofilm interactions is increased by evidence of promoted biofilm formation induced by exposure to certain phages (Lacqua et al. 2006; Tan, Dahl and Middelboe 2015; Henriksen et al. 2019). Two scenarios have been proposed for this phenomenon. In the first scenario, changes in biofilm are thought to occur as a consequence of the specific bacterial receptor used by the phage. Mutations in these receptors occur as a response to infection and may lead to changes in the biofilm cells that result in increased biofilm formation (Scanlan and Buckling 2012; Fernández et al. 2017; Henriksen et al. 2019). The second scenario suggests that some phages may benefit from increased biofilm formation, with entrapment of phages in the biofilm matrix providing protection against harsh environmental factors (Agún et al. 2018; Gabiatti et al. 2018). In this scenario, an increase of the biofilm is beneficial for both bacteria and phage.

Overall, the potential of phages to control biofilm infections is clear. However, the complexity and diversity of phage-biofilm interactions limit broad conclusions and call for more research before phage therapy becomes a real solution for biofilm-related infections.

\section{Evolution of bacterial resistance to phages}

One of the major concerns in phage therapy is the possible emergence of bacteriophage-insensitive mutants (BIMs) that could hamper the success of this therapy (Fig. 1E). Over the last years, several studies have addressed the problem of bacterial resistance to phages, demonstrating that the emergence of phageresistant mutants is frequent and almost unavoidable (Oechslin 2018; McCallin and Oechslin 2019). The resistance mechanisms used by bacteria to counter-attack phage evasion include, among others: (i) prevention of phage adsorption by loss or modification of bacterial receptors; (ii) prevention of phage DNA entry by superinfection exclusion systems; (iii) degradation of phage DNA by restriction-modification (R-M) systems and other related systems (BREX, DISARM, etc) or by CRISPR-Cas systems; (iv) use of abortive infection systems that block phage replication, transcription or translation; or (v) cyclic oligonucleotide-based antiphage signalling systems (Labrie, Samson and Moineau 2010; Bernheim and Sorek 2020).

A number of in vitro studies have reported the emergence of BIMs within a short period of time after phage treatment (Fu et al. 2010; Le et al. 2014; Oechslin et al. 2016; Pires et al. 2017b). In most of these studies, bacterial resistance to phages was caused by mutations on genes encoding phage receptors, which include lipopolysaccharides, outer membrane proteins, capsules, flagella, pili, among others. The emergence of phage-resistant variants has also been noticed in vivo in several animal models as well as in human pilot studies and case reports (Oechslin 2018; McCallin and Oechslin 2019). However, some studies have highlighted the fact that the evolution of resistance observed in vitro does not resemble what actually happens in vivo. For example, Oechslin et al. studied the efficacy of a phage cocktail in the 
treatment of $P$. aeruginosa endocarditis and observed that BIMs emerged in vitro but not in vivo (Oechslin et al. 2016). According to the authors, this occurred probably because the bacterial mutations on phage receptors rendering them resistant might incur fitness costs, with the bacteria becoming less virulent and therefore easier to eliminate by the immune system. Other authors have also reported the attenuated virulence of BIMs in consequence of modifications in cell surface receptors for other bacterial species (Filippov et al. 2011; León and Bastías 2015; Sumrall et al. 2019).

Bacterial resistance to phages can be circumvented using different approaches (McCallin and Oechslin 2019). The most common is the combination of multiple phages, preferentially targeting different receptors and with complementary host ranges, in a single preparation, which is usually known as a phage cocktail. In addition to displaying a larger coverage against a particular bacterial species, such cocktails can also arrest the emergence of BIMs. These are the main reasons behind the preferred use of phage cocktails over single phage preparations in therapy. Phage cocktails might have a fixed composition covering a broad host range (prêt-à-porter) or a customized formulation designed for a particular patient (sur-mesure) (Pirnay et al. 2011). Another strategy commonly used to deal with the problem of resistance during phage treatment is the replacement of the phage against which the bacteria developed resistance by a phage that is active against the resistant variant. While this is not easy for antibiotics, when it comes to phages it can be quite simple given their abundance and diversity in nature as a result of their constant co-evolution with bacteria (Rohde, Wittmann and Kutter 2018). Lastly, the combination of phages with antibiotics or other antimicrobial agents can also be used to avoid the development of bacterial resistance and to improve the therapeutic efficacy (see below for more detail) (Torres-Barceló and Hochberg 2016; Tagliaferri, Jansen and Horz 2019).

\section{Regulatory framework of phage therapy}

Regulatory authorities have classified phages as biological substances and, as such, phages fall within the scope of the pharmaceutical legislation (Pelfrene et al. 2016; Reindel and Fiore 2017). The regulatory framework in the European Union and in the United States stipulates that a marketing authorization is required for medicinal products prepared industrially or manufactured by a method involving an industrial process (Fig. 1F). As such, marketing a phage product requires proof of both safety and efficacy, and also of quality by manufacture under GMP (Directive 2001/20/EC 2001; Pelfrene, Sebris and Cavaleri 2019). GMP compliance requires extensive financial resources (Pelfrene et al. 2016; Jault et al. 2019) and is therefore a critical obstacle for hospitals or non-for-profit phage therapy centres. Current legislation calls also for predetermined qualitative and quantitative evaluation of every constituent of the medicinal product. For phages, recommended criteria (Parracho, Burrowes and Enright 2012; Pelfrene et al. 2016) include the absence of prophages and antibiotic resistance in the bacteria used to produce the phage(s), the lytic (non-temperate) and specific activity of individual phages on the target bacteria, the control for impurities (e.g. endotoxins, residual reagents) in phage preparations, and the test for potency and purity of the phages. This strict regulation is somehow suitable for phage cocktails of fixed composition (prêt-à-porter) manufactured at industrial scale, but is certainly inadequate for patient-specific, customized, phage cocktails (sur-mesure) whose composition is variable and not intended for large-scale distribution (Directive 2001/83/EC 2001; Pelfrene, Sebris and Cavaleri 2019) (Pirnay et al. 2011).

Discussions between phage sponsors and regulatory agencies are ongoing to set more satisfactory regulations for personalized phage therapy. The European Union currently allows for a few exceptions on the requirement to obtain a product license, which apply to the magistral formula (any medicinal product prepared in a pharmacy in accordance with a prescription for an individual patient (Nahler 2009a)) and the officinal formula (any medicinal product which is prepared in a pharmacy in accordance with the prescriptions of a pharmacopoeia and is intended to be supplied directly to the patients served by the same pharmacy (Nahler 2009b)), and for any advanced therapy medicinal product (ATMP, medicinal product which is either a gene therapy medicinal product, a somatic cell therapy medicinal product, or a tissue engineered product), if prepared on a 'non-routine basis according to specific quality standards, and used within the same Member State in a hospital under the exclusive professional responsibility of a medical practitioner, in order to comply with an individual medical prescription for a custom-made product for an individual patient' (Directive 2001/83/EC 2001; Pelfrene, Sebris and Cavaleri 2019). An exemption is applied also for compassionate use, a treatment option that allows an unauthorized (in development) medicine to be made available to groups of patients who have a disease with no satisfactory authorized therapies and who cannot enter clinical trials. However, compassionate use is only allowed for medicines undergoing clinical trials or that have entered the marketing authorization application process (Compassionate use | European Medicines Agency 2004; Pelfrene, Sebris and Cavaleri 2019).

Due to the current unsatisfactory regulatory framework, Member States of the European Union are finding national solutions for phage therapy regulation. The Belgian authorities are pioneering phage therapy regulations in Western countries by establishing a national regulation of magistral preparation of tailor-made phage medicines (Pirnay et al. 2018). The regulation requires issuing of a monograph that judges in written form the quality of the phage active pharmaceutical ingredient (API) to be used for the preparation of the medicinal product. Every stock of the phage therapy medicinal product is then tested by a Belgian approved laboratory to confirm the phage(s) comply with the phage API monograph(s), issuing a certificate of analysis that approves its use. A pharmacist then uses the certified phage stock for preparing a customized medicinal product based on the prescription of a physician (Pirnay et al. 2018). This process has already allowed the implementation of phage therapy in Belgium, but it is not yet ideal as all responsibility is given to the prescriber and the pharmacist (Fauconnier 2017). Similar regulatory principles were already in practice, for example, in Georgia and Russia. In Georgia, ready-to-use phage medicines require a marketing authorization according to regular regulation, while customized phage preparations may be prepared as magistral preparation in an authorized pharmacy (Parfitt 2005). The Russian pharmacopeia includes a monograph on phages for prophylactic and therapeutic use (Russian Pharmacopoeia OFS.1.7.1.0002.15 2020).

Other countries are also finding similar solutions. France has issued recommendations for the use of phage medicinal products under the nominative Temporary Authorization for Use (ATUn) (Phagothérapie 2016). An ATUn can be issued by hospital pharmacies, for a single patient who cannot participate in a clinical trial, at the request and under the responsibility of the prescribing physician, allowing for the use of a medicinal 
product without market approval if its efficacy and safety balance is presumed favourable for the patient, in the absence of any approved treatment. In the United States, phages can be and have been used following the Food and Drug Administration (FDA) emergency investigational new drug (eIND) pathway (Schooley et al. 2017; LaVergne et al. 2018).

Further clinical evidence of the success of phage therapy in human trials conducted to modern standards would help foster regulatory advance (Pelfrene et al. 2016), but current regulatory issues affect also the conduct of clinical trials. A new provision in the regulatory framework of the European Union may facilitate clinical trials with phage medicinal products, by exempting GMP requirements in the preparation of investigational medicine products (IMPs), 'where this process is carried out in hospitals, health centers or clinics legally authorized in the Member State concerned to carry out such process and if the IMPs are intended to be used exclusively in hospitals, health centers or clinics taking part in the same clinical trial in the same Member State' (Regulation (EU) No 536/2014 2014).

In summary, current regulations will certainly undergo serious modifications before a fully practicable regulation is implemented for phage therapy, as well as other customized medicinal products meant to be tailored to an individual patient.

\section{THE FUTURE OF PHAGE THERAPY}

\section{Phages in One Health approach}

It is estimated that at least 6 out of 10 known infectious diseases in humans are originated in animals (Zoonotic Diseases | One Health | CDC 2017). Moreover, the selective pressure on phytobacteria drives evolution in a vast number of defence mechanisms, which can result in increased virulence towards humans, especially those with advanced age, immunodeficiency or cancer (Erken, Lutz and McDougald 2013; Falkinham, Pruden and Edwards 2015). The One Health concept recognizes that the health of humans and animals as well as our environment are all intertwined. To improve the lives of all living species, the One Health program proposes the integration of human medicine, veterinary medicine and environmental science (http://www.onehealthinitiative.com/). Agriculture and food safety are also included in this holistic and multi-sectoral approach to tackle antimicrobial resistance (Baum et al. 2017; Hernando-Amado et al. 2019). Although microorganisms will inevitably develop resistance towards antibiotics as a consequence of genetic mutations or horizontal gene transfer, the problem of resistance is worsened by the misuse of antibiotics since their discovery. A clear example is the use of antibiotics as growth promoters at livestock farms, which impelled the European Union to create stricter regulations to control their widespread usage (Kittler et al. 2017). To mitigate the spread of antimicrobial resistance, new alternative therapeutics under the One Health view are needed. Since their discovery, phages are being applied for the control of bacterial proliferation in several microbiomes, such as humans (as reviewed above), animals (Oliveira, Sereno and Azeredo 2010), several environmental settings (e.g. wastewater treatments) (Withey et al. 2005), and on food industry (Abuladze et al. 2008). A good example of the global use of phages are the diverse application opportunities in food industry, where they can be used at all stages of food processing, from slathering and crops to food transportation (reviewed by (Goodridge and Bisha 2011)), even improving the shelf life of food products (Alves et al. 2019). In fact, several phage-based products to be applied in food-stuff have already received the GRAS (generally recognized as safe) classification by the FDA in the United States (Sarhan and Azzazy 2015). Therefore, the use of phages is consistent with the One Health approach as they can be applied in different settings (e.g. food, animals or crops) thus preventing the overuse of antibiotics and the dissemination of antibiotic resistance to humans (Kittler et al. 2017).

\section{Emerging approaches}

The use of phages for the control of bacterial infections might be improved via combination with other agents, especially when targeting the complex biofilm communities (Koo et al. 2017). These combined therapies have often the advantage of limited development of resistance towards agents with distinct modes of action due to the fitness cost associated with resistance against multiple factors (Torres-Barceló and Hochberg 2016; Chaudhry et al. 2017).

Probably the most obvious combination is that of phages and antibiotics (Fig. 1G). When used simultaneously, phages and antibiotics have shown synergistic effects and effectiveness against planktonic cells (Bedi, Verma and Chhibber 2009; Nouraldin et al. 2016; Jansen et al. 2018; Yazdi, Bouzari and Ghaemi 2018) and (especially old) biofilms (Bedi, Verma and Chhibber 2009; Rahman et al. 2011; Chaudhry et al. 2017; Akturk et al. 2019), where the individual treatments had restricted success. In cases where repeated treatment with phages increased biofilm production, the combined use of phage and antibiotics resulted in biofilm eradication (Henriksen et al. 2019). Structural changes in the biofilm caused by one or both agents may be behind the enhanced efficacy. For example, removal of peripheral cells by the phage may lead to increased resource availability for inner cells and improve their metabolic state, making the cells more susceptible towards phages and certain antibiotics (Chaudhry et al. 2017). Antibiotics may also themselves cause changes in the biofilm architecture and thereby enable increased invasion of biofilms by phages (Díaz-Pascual et al. 2019).

Synergism between antibiotics and phages does not happen for all phage-antibiotic combinations (Knezevic et al. 2013; Kamal and Dennis 2015; Jansen et al. 2018) and high doses of antibiotics can also antagonize phage propagation (Dickey and Perrot 2019). This is particularly evident when using antibiotics that target cell protein synthesis (Akturk et al. 2019). But in some cases, even though no synergism in antimicrobial activity is observed, the combined use of phages and antibiotics significantly reduces or even prevents the development of antibioticand phage-resistant bacteria (Coulter et al. 2014; Dickey and Perrot 2019).

While several studies have looked into the effect of phageantibiotic therapies, few have developed a rational approach to explore the bacterial response to these agents. An example of such strategy is the isolation of phages targeting specific outer membrane proteins that are used by bacteria as multidrug efflux pumps. Development of resistance to this phage would require the bacteria to change the efflux pump and therefore increase sensitivity against certain antibiotic classes (Chan et al. 2016). This approach was successfully employed to save a patient suffering from a chronic prosthetic vascular graft infection caused by $P$. aeruginosa, in which phage OMKO1 binding to efflux pump proteins was used in combination with ceftazidime; evolution of phage resistance led to increased antibiotic sensitivity and the infection was resolved (Chan et al. 2018). Approaches like this are not only efficient but also extend the lifetime of our current antibiotics. 
Phages can also be co-administered with enzymes for improved activity. For example, depolymerases can be used together with phages that do not naturally express them to improve their activity against biofilms (Gutiérrez et al. 2015a). DNAse enzymes can also be used together with phages to degrade the DNA component of the biofilm matrix and improve phage activity (Hughes et al. 2006). Other successful cases combined phages with chlorine (Zhang and $\mathrm{Hu}$ 2013), triclosan, chlorhexidine, hydrogen peroxide (Agún et al. 2018), cobalt (II) sulphate (Chhibber, Nag and Bansal 2013), xylitol (Chhibber, Bansal and Kaur 2015), honey (Oliveira et al. 2017) and probiotics (Woo and Ahn 2014).

The modification of phage genomes is also being explored to improve phage therapy outcomes (Fig. 1H). This approach is being fuelled by recent advances in the synthetic biology field, with many techniques now available to engineer phage genomes (Martel and Moineau 2014; Ando et al. 2015; Pires et al. 2016; Kilcher et al. 2018). The host range of a phage is one of the main targets to engineer. While the high host specificity of phages is advantageous by preventing targeting of beneficial bacteria, it also implies that it is almost impossible to target all strains within a given species using a single phage. Tailored control of a phage's host range is therefore a major goal in phage therapy. Working towards this goal, several studies have swapped receptor-binding protein genes between phages of different families, successfully exchanging the host range of the phage. This has been possible between phages infecting the same (Yoichi et al. 2005; Mahichi et al. 2009) or different species (Ando et al. 2015). Others had fused a heterologous receptor binding domain to the receptor binding protein of a phage, thereby increasing the phage host range (Marzari et al. 1997; Heilpern and Waldor 2003).

Phages can also be engineered to deliver specific cargo to enhance the phage antimicrobial activity. For example, enzymes such as dispersin B and lactonase have been engineered into phage T7 to increase the phage activity against biofilms (Lu and Collins 2007; Pei and Lamas-Samanamud 2014). Dispersin $\mathrm{B}$, a glycoside hydrolase, is expressed at high levels during T7 infection and released upon cell lysis into the biofilm environment, where it degrades the matrix; by doing so, dispersin B increases the phage efficacy on removing both bacteria and matrix from the biofilm (Lu and Collins 2007). Lactonase was also engineered into phage $\mathrm{T} 7$, but to interfere with the bacterial quorum sensing, making use of its ability to inactivate the quorum sensing acylated homoserine lactones (Pei and Lamas-Samanamud 2014). Inactivation of the quorum sensing molecules interferes with biofilm formation and leads to improved biofilm control by the engineered phage. Curiously, this strategy was shown to work in multi-species biofilms, where quorum sensing molecules of one species also increase biofilm formation of the second species, and inhibition of the molecules by the lactonase reduces biofilm formation in both species. This may therefore be an interesting alternative treatment against multi-species biofilms in the future.

While most engineering efforts have centred on lytic phages, temperate phages have also been the subject of a few engineering experiments for phage therapy purposes. The most obvious approach consists on genetically modifying phages to become exclusively lytic. This has been accomplished by deletion of the genomic module responsible for the establishment of lysogeny (Dorscht et al. 2009; Zhang et al. 2013; Kilcher et al. 2018). The creation of virulent mutants of otherwise temperate phages can easily extend the number and diversity of phages available for therapeutic purposes. A great example of the value of this approach is the recent use of a cocktail composed of one natural lytic phage and two engineered temperate phages to successfully treat a 15-year-old patient with cystic fibrosis with a disseminated Mycobacterium abscessus infection (Dedrick et al. 2019). The temperate phages were engineered to become lytic via removal of the repressor of the lytic cycle, and the cocktail was administered intravenously and was well tolerated. Genetically engineered phages are not readily accepted for phage therapy due to the inherent ethical issues of genetically modified organisms (GMOs) but this case study clearly shows that engineering approaches are useful. The possibility of using temperate phages engineered into lytic forms in phage therapy increases the number of phages available for therapeutic use, by reducing/removing the risk of transduction of bacterial genetic information (e.g. virulence-related genes) mediated by temperate phages (Monteiro et al. 2019).

Temperate phages have also been engineered to deliver synthetic gene networks, exploiting their natural capacity to integrate into the host bacterium chromosome, where the phage expresses the molecule of interest. Phages have been modified as adjuvants to antibiotics, by codifying dominant antibiotic sensitive genes (Edgar et al. 2012) or CRISPR-Cas systems (Bikard et al. 2014; Yosef et al. 2015) that revert antibiotic resistance in bacteria, or by codifying CRISPR-Cas systems designed to target bacterial cells (Park et al. 2017).

Overall, engineering approaches can potentially improve the antimicrobial properties of phages and create innovative strategies for fighting bacterial infections. The consequences of genetic manipulation of phage genomes must be carefully addressed, but phage engineering strategies should be effectively considered as a therapeutic option. Additionally, engineered phages have easier patentability than natural phages and may therefore have more commercial interest.

\section{Can phage resistance become a global problem?}

Phage therapy frequently raises the question of whether the global use of phages could lead to a widespread problem similar to antibiotic resistance. A definitive answer does not exist.

First, phages will unlikely be used as a first line treatment against bacterial infections as it happens with antibiotics. In a future perspective, phage therapy is expected to be applied only in clinical cases of patients who experienced the failure of antibiotic treatments. Additionally, contrary to antibiotic therapy, phage preparations for therapeutic applications are expected to be developed in a personalized way by formulating phage cocktails that might delay the emergence of bacterial resistance to phages.

In the scenario of phages being extensively used in the future both as therapeutic and as environmental bio-control agents, it is possible that a strong selective pressure is imposed towards the development of resistant bacteria. Still, it seems improbable that no phage will be available in nature to infect a bacteria that has become resistant to a previous phage. In fact, the long and continuous co-evolution of phages and bacteria (Dion, Oechslin and Moineau 2020) have resulted in bacteria evolving a range of mechanisms to avoid phage predation, and in phages developing effective counter-strategies to evade the antiviral systems (Samson et al. 2013). This arms race between phages and their bacterial hosts will not come to an end and, despite the emergence of resistant bacteria, phages will certainly find a way to ensure their propagation. The use of strategies as combined therapies and genome engineering may be an additional aid to prevent the spread of phage resistance. Still, further studies are 
required to guarantee that the global use of phages will not eventually compromise its efficacy.

\section{FINAL REMARKS}

In an era of global crisis for antibiotics, phage therapy has emerged as a potential alternative with already proven cases of clinical success. The generic use of phages for biocontrol meets the One Health Approach and is well aligned with the recently established European Green Deal (European Commission 2019) that recommends reducing significantly the use of antibiotics in food production. On the other hand, scientific advances have contributed to a better knowledge of phage-bacteria interaction enabling a safer and more efficient phage therapy. So, the conditions needed for the reintroduction of phage therapy as a therapeutic practice are met. Nevertheless, the widespread use of phage therapy creates additional challenges that go beyond the clinic standpoint and carries extra demands. These include (i) the need of increasing phage collections of reference phage banks; (ii) the development of efficient phage screening methods for the fast identification of the therapeutic phage; (iii) the establishment of efficient phage therapy strategies that tackle infectious biofilms; (iv) the set-up of phage production protocols that assure quality and safety of phage preparations and (v) the guarantee of stability of phage preparation during storage and transport.

As infectious diseases have no borders, a global action plan to make phage therapy worldwide available is needed. This obviously requires an active collaboration between countries for overcoming logistic and regulatory challenges, and between clinicians and scientists for filling current knowledge gap and fostering advances in the field.

\section{FUNDING}

This study was supported by the Portuguese Foundation for Science and Technology (FCT) under the scope of the project PTDC/BBB-BSS/6471/2014 ( POCI-01-0145-FEDER-016643); the strategic funding of UIDB/04469/2020 unit and BioTecNorte operation (NORTE-01-0145-FEDER-000004) funded by European Regional Development Fund under the scope of Norte2020Programa Operacional Regional do Norte. DPP and GP are supported by FCT through the grants SFRH/BPD/116187/2016 and SFRH/BD/117365/2016, respectively.

Conflicts of Interest. None declared.

\section{REFERENCES}

Abuladze T, Li M, Menetrez MY et al. Bacteriophages reduce experimental contamination of hard surfaces, tomato, spinach, broccoli, and ground beef by Escherichia coli 0157:H7. Appl Environ Microbiol 2008;74:6230-8.

Agún S, Fernández L, González-Menéndez E et al. Study of the interactions between bacteriophage phiIPLA-RODI and four chemical disinfectants for the elimination of Staphylococcus aureus contamination. Viruses 2018;10:103.

Akturk E, Oliveira H, Santos SB et al. Synergistic action of phage and antibiotics: parameters to enhance the killing efficacy against mono and dual-species biofilms. Antibiotics 2019;8:103.

Alves D, Marques A, Milho C et al. Bacteriophage $\phi$ IBB-PF7A loaded on sodium alginate-based films to prevent microbial meat spoilage. Int J Food Microbiol 2019;291:121-7.
Alves DR, Perez-Esteban P, Kot W et al. A novel bacteriophage cocktail reduces and disperses Pseudomonas aeruginosa biofilms under static and flow conditions. Microb Biotechnol 2015, DOI:10.1111/1751-7915.12316.

Ando H, Lemire S, Pires DP et al. Engineering modular viral scaffolds for targeted bacterial population editing. Cell Syst 2015;1:187-96.

Aslam S, Yung G, Dan J et al. Bacteriophage treatment in a lung transplant recipient. J Hear Lung Transplant 2018;37:S155-6.

Baum SE, Machalaba C, Daszak P et al. Evaluating one health: are we demonstrating effectiveness? One Heal 2017;3:5-10.

Bedi MS, Verma V, Chhibber S. Amoxicillin and specific bacteriophage can be used together for eradication of biofilm of Klebsiella pneumoniae B5055. World J Microbiol Biotechnol 2009;25:1145-51.

Bernheim A, Sorek R. The pan-immune system of bacteria: antiviral defence as a community resource. Nat Reu Microbiol 2020;18:113-9.

Bikard D, Euler CW, Jiang W et al. Exploiting CRISPR-Cas nucleases to produce sequence-specific antimicrobials. Nat Biotechnol 2014;32:1146-50.

Botka T, Pantůček R, Mašlaňová I et al. Lytic and genomic properties of spontaneous host-range Kayvirus mutants prove their suitability for upgrading phage therapeutics against staphylococci. Sci Rep 2019;9, DOI:10.1038/s41598-019-41868-w.

Bull JJ, Christensen KA, Scott C et al. Phage-bacterial dynamics with spatial structure: self organization around phage sinks can promote increased cell densities. Antibiotics 2018;7:8.

Cassini A, Högberg LD, Plachouras D et al. Attributable deaths and disability-adjusted life-years caused by infections with antibiotic-resistant bacteria in the EU and the European Economic Area in 2015: a population-level modelling analysis. Lancet Infect Dis 2019;19:56-66.

Centers for Disease Control. Antibiotic Resistance Threats in the United States, US, 2019, DOI: http://dx.doi.org/10.15620/cdc: 82532.

Chan BK, Sistrom M, Wertz JE et al. Phage selection restores antibiotic sensitivity in MDR Pseudomonas aeruginosa. Sci Rep 2016;6:1-8.

Chan BK, Turner PE, Kim S et al. Phage treatment of an aortic graft infected with Pseudomonas aeruginosa. Evol Med Public Heal 2018;2018:60-6.

Chanishvili N. Phage therapy-history from Twort and d'Herelle through Soviet experience to current approaches. Adv Virus Res 2012;83:3-40.

Chaudhry WN, Concepcion-Acevedo J, Park T et al. Synergy and Order Effects of Antibiotics and Phages in Killing Pseudomonas aeruginosa Biofilms. PLoS One 2017;12:e0168615.

Chhibber S, Bansal S, Kaur S. Disrupting the mixed-species biofilm of klebsiella pneumoniae B5055 and pseudomonas aeruginosa PAO using bacteriophages alone or in combination with xylitol. Microbiol 2015;161:1369-77.

Chhibber S, Nag D, Bansal S. Inhibiting biofilm formation by Klebsiella pneumoniae B5055 using an iron antagonizing molecule and a bacteriophage. BMC Microbiol 2013;13:174.

Clokie MR, Millard AD, Letarov AV et al. Phages in nature. Bacteriophage 2011;1:31-45.

Colom J, Cano-Sarabia M, Otero J et al. Microencapsulation with alginate/CaCO 3: A strategy for improved phage therapy. Sci Rep 2017;7:41441.

Commission E. Communication from the Commission to the European Parliament, the European Council, the Council, the European Economic and Social Committee and the Committee of the Regions. Brussels: Publications Office of the European Union, 2019. 
Compassionate use | European Medicines Agency. Regulation (EC) No 726/2004 of the European Parliament and of the Council of 31 March 2004 laying down Community procedures for the authorisation and supervision of medicinal products for human and veterinary use and establishing a European Medicines Agency (2004) Official Journal L136, p. 65. 2004.

Cornax R, Moriñigo MA, Paez IG et al. Application of direct plaque assay for detection and enumeration of bacteriophages of Bacteroides fragilis from contaminated-water samples. Appl Environ Microbiol 1990;56:3170-3.

Cortés P, Cano-Sarabia M, Colom J et al. Nano/Micro formulations for bacteriophage delivery. Methods in Molecular Biology. Vol 1693, New York, NY: Humana Press, 2018, 271-83.

Costerton JW, Lewandowski Z, Caldwell DE et al. Microbial biofilms. Annu Reu Microbiol 1995;49:711-45.

Costerton JW, Stewart PS, Greenberg EP. Bacterial biofilms: a common cause of persistent infections. Science (80-) 1999;284:1318-22.

Coulter LB, McLean RJC, Rohde RE et al. Effect of bacteriophage infection in combination with tobramycin on the emergence of resistance in Escherichia coli and Pseudomonas aeruginosa biofilms. Viruses 2014;6:3778-86.

Curtin JJ, Donlan RM. Using bacteriophages to reduce formation of catheter-associated biofilms by Staphylococcus epidermidis. Antimicrob Agents Chemother 2006;50:1268-75.

Darch SE, Kragh KN, Abbott EA et al. Phage inhibit pathogen dissemination by targeting bacterial migrants in a chronic infection model. MBio 2017;8:e00240-17.

Davies J, Davies D. Origins and evolution of antibiotic resistance. Microbiol Mol Biol Rev 2010;74:417-33.

Dedrick RM, Guerrero-Bustamante CA, Garlena RA et al. Engineered bacteriophages for treatment of a patient with a disseminated drug-resistant Mycobacterium abscessus. Nat Med 2019;25:730-3.

Del Rio B, Martín MC, Martínez N et al. Multiplex fast real-time PCR for quantitative detection and identification of cos- and pac-type Streptococcus thermophilus bacteriophages. Appl Environ Microbiol. Vol 74. 2008, 4779-81.

Dickey J, Perrot V. Adjunct phage treatment enhances the effectiveness of low antibiotic concentration against Staphylococcus aureus biofilms in vitro. PLoS One 2019;14:e0209390.

Dion MB, Oechslin F, Moineau S. Phage diversity, genomics and phylogeny. Nat Reu Microbiol 2020;18:125-38.

Directive 2001 /20/EC. Directive 2001/20/EC of the European Parliament and of the Council of 4 April 2001 on the approximation of the laws, regulations and administrative provisions of the Member States relating to the implementation of good clinical practice in the conduct of clinical trials on medicinal products for human use (2001) Official Journal L121, p. 34, 2001.

Directive 2001 /83/EC. Directive 2001/83/EC of the European Parliament and of the Council of 6 November 2001 on the Community role relating to medicinal products for human use (2001) Official Journal L311, p. 67, 2001.

Djebara S, Maussen C, De Vos D et al. Processing phage therapy requests in a brussels military hospital: Lessons identified. Viruses 2019;11:265.

Dorscht J, Klumpp J, Bielmann R et al. Comparative genome analysis of Listeria bacteriophages reveals extensive mosaicism, programmed translational frameshifting, and a novel prophage insertion site. J Bacteriol 2009;191:7206-15.
Drake JW. Spontaneous Mutations Accumulating in Bacteriophage T4 in the Complete Absence of DNA Replication. Proc Natl Acad Sci U S A 1966;55:738-43.

Dunsing V, Irmscher T, Barbirz S et al. Purely PolysaccharideBased Biofilm Matrix Provides Size-Selective Diffusion Barriers for Nanoparticles and Bacteriophages. Biomacromolecules 2019;20:3842-54.

Duplessis C, Biswas B, Hanisch B et al. Refractory Pseudomonas bacteremia in a 2-year-old sterilized by bacteriophage therapy. J Pediatric Infect Dis Soc 2018;7:253-6.

Díaz-Pascual F, Hartmann R, Lempp M et al. Breakdown of Vibrio cholerae biofilm architecture induced by antibiotics disrupts community barrier function. Nat Microbiol 2019;4:2136-45.

Dąbrowska K. Phage therapy: What factors shape phage pharmacokinetics and bioavailability? Systematic and critical review. Med Res Rev 2019;39:med.21572.

Edgar R, Friedman N, Molshanski-Mor S et al. Reversing bacterial resistance to antibiotics by phage-mediated delivery of dominant sensitive genes. Appl Environ Microbiol 2012;78:744-51.

Erez Z, Steinberger-Levy I, Shamir M et al. Communication between viruses guides lysis-lysogeny decisions. Nature 2017;541:488-93.

Erken M, Lutz C, McDougald D. The rise of pathogens: predation as a factor driving the evolution of human pathogens in the environment. Microb Ecol 2013;65:860-8.

Fadlallah A, Chelala E, Legeais J-M. Corneal infection therapy with topical bacteriophage administration. Open Ophthalmol J 2015;9:167-8.

Falkinham J, Pruden A, Edwards M. Opportunistic premise plumbing pathogens: increasingly important pathogens in drinking water. Pathogens 2015;4:373-86.

Fauconnier A. Phage therapy regulation: From night to dawn. Viruses 2019;11:352.

Fauconnier A. Regulating phage therapy. EMBO Rep 2017;18: 198-200.

Fernández L, González S, Campelo AB et al. Low-level predation by lytic phage phiIPLA-RODI promotes biofilm formation and triggers the stringent response in Staphylococcus aureus. Sci Rep 2017;7:40965.

Fernández L, Gutiérrez D, García P et al. The perfect bacteriophage for therapeutic applications-A quick guide. Antibiotics 2019;8:126.

Ferry T, Boucher F, Fevre C et al. Innovations for the treatment of a complex bone and joint infection due to XDR Pseudomonas aeruginosa including local application of a selected cocktail of bacteriophages. J Antimicrob Chemother 2018a;73:2901-3.

Ferry $\mathrm{T}$, Leboucher $\mathrm{G}$, Fevre $\mathrm{C}$ et al. Salvage Debridement, Antibiotics and Implant Retention ("DAIR") With Local Injection of a Selected Cocktail of Bacteriophages: Is It an Option for an Elderly Patient With Relapsing Staphylococcus aureus Prosthetic-Joint Infection? Open forum Infect Dis 2018b;5:ofy269.

Filippov AA, Sergueev K V., He Y et al. Bacteriophage-Resistant Mutants in Yersinia pestis: Identification of Phage Receptors and Attenuation for Mice. Kaushal D (ed.). PLoS One 2011;6:e25486.

Fish R, Kutter E, Bryan D et al. Resolving digital staphylococcal osteomyelitis using bacteriophage-A case report. Antibiotics 2018;7:87.

Furfaro LL, Payne MS, Chang BJ. Bacteriophage Therapy: Clinical Trials and Regulatory Hurdles. Front Cell Infect Microbiol 2018;8:376. 
$\mathrm{Fu} \mathrm{W}$, Forster T, Mayer O et al. Bacteriophage cocktail for the prevention of biofilm formation by Pseudomonas aeruginosa on catheters in an in vitro model system. Antimicrob Agents Chemother 2010;54:397-404.

Gabiatti N, Yu P, Mathieu J et al. Bacterial endospores as phage genome carriers and protective shells. Appl Environ Microbiol 2018;84:e01186-18.

García-Aljaro C, Muñoz-Berbel X, Jenkins ATA et al. Surface plasmon resonance assay for real-time monitoring of somatic coliphages in wastewaters. Appl Environ Microbiol 2008;74:4054-8.

García R, Latz S, Romero J et al. Bacteriophage Production Models: An Overview. Front Microbiol 2019;10:1187.

Gonzalez-Menendez E, Fernandez L, Gutierrez D et al. Comparative analysis of different preservation techniques for the storage of Staphylococcus phages aimed for the industrial development of phage-based antimicrobial products. PLoS One 2018;13:e0205728.

González S, Fernández L, Gutiérrez D et al. Analysis of Different Parameters Affecting Diffusion, Propagation and Survival of Staphylophages in Bacterial Biofilms. Front Microbiol 2018;9:2348.

Goodridge LD, Bisha B. Phage-based biocontrol strategies to reduce foodborne pathogens in foods. Bacteriophage 2011;1:130-7.

Gordillo Altamirano FL, Barr JJ. Phage therapy in the postantibiotic era. Clin Microbiol Rev 2019;32:e00066-18.

Gutiérrez D, Briers Y, Rodríguez-Rubio L et al. Role of the Pre-neck Appendage Protein (Dpo7) from Phage vB_SepiS-phiIPLA7 as an Anti-biofilm Agent in Staphylococcal Species. Front Microbiol 2015a;6:1315.

Gutiérrez D, Vandenheuvel D, Martínez B et al. Two Phages, phiIPLA-RODI and phiIPLA-C1C, Lyse Mono- and DualSpecies Staphylococcal Biofilms. Appl Environ Microbiol 2015b;81:3336-48.

Guzmán Luna C, Costán-Longares A, Lucena F et al. Detection of somatic coliphages through a bioluminescence assay measuring phage mediated release of adenylate kinase and adenosine 5'-triphosphate. J Virol Methods 2009;161:107-13.

Harcombe WR, Bull JJ. Impact of phages on two-species bacterial communities. Appl Environ Microbiol 2005;71:5254-9.

Hargreaves KR, Clokie MRJ. Clostridium difficile phages: Still difficult? Front Microbiol 2014;5:184.

Harper D, Parracho H, Walker J et al. Bacteriophages and Biofilms. Antibiotics 2014;3:270-84.

Heilpern AJ, Waldor MK. pIIICTX, a predicted CTXphi minor coat protein, can expand the host range of coliphage fd to include Vibrio cholerae. J Bacteriol 2003;185:1037-44.

Henriksen K, Rørbo N, Rybtke ML et al. P. aeruginosa flow-cell biofilms are enhanced by repeated phage treatments but can be eradicated by phage-ciprofloxacin combinationmonitoring the phage-P. aeruginosa biofilms interactions. Pathog Dis 2019;77:ftz011.

Henry M, Biswas B, Vincent L et al. Development of a high throughput assay for indirectly measuring phage growth using the OmniLog TM system. Bacteriophage 2012;2:159-67.

Hernando-Amado S, Coque TM, Baquero F et al. Defining and combating antibiotic resistance from One Health and Global Health perspectives. Nat Microbiol 2019;4:1432-42.

Hietala V, Horsma-Heikkinen J, Carron A et al. The Removal of Endo- and Enterotoxins From Bacteriophage Preparations. Front Microbiol 2019;10:1674.

Hobley L, Harkins C, MacPhee CE et al. Giving structure to the biofilm matrix: an overview of individual strategies and emerging common themes. FEMS Microbiol Rev 2015;39: 649-69.

Hoyle N, Zhvaniya P, Balarjishvili $\mathrm{N}$ et al. Phage therapy against Achromobacter xylosoxidans lung infection in a patient with cystic fibrosis: a case report. Res Microbiol 2018;169:540-2.

Hughes G, Walker JT, Sharp R et al. Bacteriophage for the treatment of bacterial biofilms. 2006.US7758856B2.

Høyland-Kroghsbo NM, Maerkedahl RB, Svenningsen S Lo. A quorum-sensing-induced bacteriophage defense mechanism. MBio 2013;4:e00362-12.

Høyland-Kroghsbo NM, Paczkowski J, Mukherjee S et al. Quorum sensing controls the Pseudomonas aeruginosa CRISPRCas adaptive immune system. Proc Natl Acad Sci U S A 2017;114:131-5.

Jansen M, Wahida A, Latz S et al. Enhanced antibacterial effect of the novel T4-like bacteriophage KARL-1 in combination with antibiotics against multi-drug resistant Acinetobacter baumannii. Sci Rep 2018;8:1-12.

Jault P, Leclerc T, Jennes S et al. Efficacy and tolerability of a cocktail of bacteriophages to treat burn wounds infected by Pseudomonas aeruginosa (PhagoBurn): a randomised, controlled, double-blind phase 1/2 trial. Lancet Infect Dis 2019;19:35-45.

Jennes S, Merabishvili M, Soentjens $\mathrm{P}$ et al. Use of bacteriophages in the treatment of colistin-only-sensitive Pseudomonas aeruginosa septicaemia in a patient with acute kidney injury-a case report. Crit Care 2017;21:129.

Kamal F, Dennis JJ. Burkholderia cepacia complex Phage-Antibiotic Synergy (PAS): antibiotics stimulate lytic phage activity. Appl Environ Microbiol 2015;81:1132-8.

Kay MK, Erwin TC, McLean RJC et al. Bacteriophage ecology in Escherichia coli and Pseudomonas aeruginosa mixed-biofilm communities. Appl Environ Microbiol 2011;77:821-9.

Khawaldeh A, Morales S, Dillon B et al. Bacteriophage therapy for refractory Pseudomonas aeruginosa urinary tract infection. J Med Microbiol 2011;60:1697-700.

Kilcher S, Studer P, Muessner C et al. Cross-genus rebooting of custom-made, synthetic bacteriophage genomes in L-form bacteria. Proc Natl Acad Sci USA 2018;115:567-72.

Kim S, Rahman M, Seol SY et al. Pseudomonas aeruginosa bacteriophage PA1 $\varnothing$ requires type IV pili for infection and shows broad bactericidal and biofilm removal activities. Appl Environ Microbiol 2012;78:6380-5.

Kittler S, Wittmann J, Mengden RALP et al. The use of bacteriophages as One-Health approach to reduce multidrugresistant bacteria. Sustain Chem Pharm 2017;5:80-3.

Knezevic P, Curcin S, Aleksic V et al. Phage-antibiotic synergism: a possible approach to combatting Pseudomonas aeruginosa. Res Microbiol 2013;164:55-60.

Koo H, Allan RN, Howlin RP et al. Targeting microbial biofilms: Current and prospective therapeutic strategies. Nat Rev Microbiol 2017;15:740-55.

Kropinski AM, Mazzocco A, Waddell TE et al. Enumeration of bacteriophages by double agar overlay plaque assay. In: Clokie MR Kropinski AM (eds). Bacteriophages: Methods and Protocols. Vol 501, New York, NY: Humana Press, 2009, 69-76.

Labrie SJ, Samson JE, Moineau S. Bacteriophage resistance mechanisms. Nat Reu Microbiol 2010;8:317-27.

Lacqua A, Wanner O, Colangelo $\mathrm{T}$ et al. Emergence of biofilmforming subpopulations upon exposure of Escherichia coli to environmental bacteriophages. Appl Environ Microbiol 2006;72:956-9.

LaVergne S, Hamilton T, Biswas B et al. Phage therapy for a multidrug-resistant Acinetobacter baumannii craniectomy site infection. Open forum Infect Dis 2018;5:ofy064. 
Law N, Logan C, Yung G et al. Successful adjunctive use of bacteriophage therapy for treatment of multidrug-resistant Pseudomonas aeruginosa infection in a cystic fibrosis patient. Infection 2019;47:665-8.

Lehman SM, Donlan RM. Bacteriophage-mediated control of a two-species biofilm formed by microorganisms causing catheter-associated urinary tract infections in an in vitro urinary catheter model. Antimicrob Agents Chemother 2015;59:1127-37.

Le S, Yao X, Lu S et al. Chromosomal DNA deletion confers phage resistance to Pseudomonas aeruginosa. Sci Rep 2014;4:4738.

Leszczyński P, Weber-Dąbrowska B, Kohutnicka M et al. Successful eradication of methicillin-resistant Staphylococcus aureus (MRSA) intestinal carrier status in a healthcare worker - Case report. Folia Microbiol 2006;51:236-8.

Leung SSY, Parumasivam T, Gao FG et al. Effects of storage conditions on the stability of spray dried, inhalable bacteriophage powders. Int J Pharm 2017;521:141-9.

León M, Bastías R. Virulence reduction in bacteriophage resistant bacteria. Front Microbiol 2015;6:343.

Loś M, Golec P, Loś JM et al. Effective inhibition of lytic development of bacteriophages lambda, P1 and T4 by starvation of their host, Escherichia coli. BMC Biotechnol 2007;7:13.

Lu TK, Collins JJ. Dispersing biofilms with engineered enzymatic bacteriophage. Proc Natl Acad Sci U S A 2007;104: 11197-202.

Ly-Chatain MH, Durand L, Rigobello V et al. Direct Quantitative Detection and Identification of Lactococcal Bacteriophages from Milk and Whey by Real-Time PCR: Application for the Detection of Lactococcal Bacteriophages in Goat's Raw Milk Whey in France. Int J Microbiol 2011;2011:594369.

Mahichi F, Synnott AJ, Yamamichi K et al. Site-specific recombination of T2 phage using IP008 long tail fiber genes provides a targeted method for expanding host range while retaining lytic activity. FEMS Microbiol Lett 2009;295:211-7.

Malik B. Bhattacharyya S. Antibiotic drug-resistance as a complex system driven by socio-economic growth and antibiotic misuse. Sci Rep 2019;9.

Malik DJ, Sokolov IJ, Vinner GK et al. Formulation, stabilisation and encapsulation of bacteriophage for phage therapy. Adv Colloid Interface Sci 2017;249:100-33.

Manning AJ, Kuehn MJ. Contribution of bacterial outer membrane vesicles to innate bacterial defense. BMC Microbiol 2011;11:258.

Martel B, Moineau S. CRISPR-Cas: an efficient tool for genome engineering of virulent bacteriophages. Nucleic Acids Res 2014;42:9504-13.

Marza JAS, Soothill JS, Boydell P et al. Multiplication of therapeutically administered bacteriophages in Pseudomonas aeruginosa infected patients. Burns 2006;32:644-6.

Marzari R, Sblattero D, Righi $M$ et al. Extending filamentous phage host range by the grafting of a heterologous receptor binding domain. Gene 1997;185:27-33.

Ma Y, Pacan JC, Wang Q et al. Enhanced alginate microspheres as means of oral delivery of bacteriophage for reducing Staphylococcus aureus intestinal carriage. Food Hydrocoll 2012;26: 434-40.

McCallin S, Brüssow H. Clinical trials of bacteriophage therapeutics. Bacteriophages. Springer International Publishing, 2017, $1-29$.

McCallin S, Oechslin F. Bacterial resistance to phage and its impact on clinical therapy. Phage Therapy: A Practical Approach, Switzerland AG: Springer International Publishing, 2019, 59-88.
McCallin S, Sacher JC, Zheng J et al. Current state of compassionate phage therapy. Viruses 2019;11:343.

Melo L, França A, Brandão A et al. Assessment of Sep1virus interaction with stationary cultures by transcriptional and flow cytometry studies. FEMS Microbiol Ecol 2018;94:fiy143.

Melo LDR, Veiga P, Cerca N et al. Development of a phage cocktail to control proteus mirabilis catheter-associated urinary tract infections. Front Microbiol 2016;7:1024.

Merabishvili M, Monserez R, Van Belleghem J et al. Stability of bacteriophages in burn wound care products. PLoS One 2017;12:e0182121.

Merabishvili M, Pirnay J-P, Verbeken G et al. Quality-controlled small-scale production of a well-defined bacteriophage cocktail for use in human clinical trials. Ojcius DM (ed.). PLoS One 2009;4:e4944.

Merabishvili M, Pirnay JP, De Vos D. Guidelines to compose an ideal bacteriophage cocktail. Methods in Molecular Biology. Vol 1693, New York, NY: Humana Press Inc., 2018, 99-110.

Michelsen O, Cuesta-Dominguez Á, Albrechtsen B et al. Detection of bacteriophage-infected cells of Lactococcus lactis by using flow cytometry. Appl Environ Microbiol 2007;73:7575-81.

Międzybrodzki R, Borysowski J, Weber-Dąbrowska B et al. Clinical aspects of phage therapy. Adv Virus Res 2012;83:73-121.

Monteiro R, Pires DP, Costa AR et al. Phage Therapy: Going Temperate? Trends Microbiol 2019;27:368-78.

Mutti M, Corsini L. Robust Approaches for the Production of Active Ingredient and Drug Product for Human Phage Therapy. Front Microbiol 2019;10:2289.

Nahler G. magistral formula. Dictionary of Pharmaceutical Medicine. Springer: Vienna, 2009a, 109.

Nahler G. officinal formula. Dictionary of Pharmaceutical Medicine. Springer: Vienna, 2009b, 125.

Nelson MI, Mahfuz M, Chhabra P et al. Genetic Diversity of Noroviruses Circulating in a Pediatric Cohort in Bangladesh. $J$ Infect Dis 2018;218:1937-42.

Ng W-L, Bassler BL. Bacterial Quorum-Sensing Network Architectures. Annu Rev Genet 2009;43:197-222.

Nir-Paz R, Gelman D, Khouri A et al. Successful Treatment of Antibiotic-resistant, Poly-microbial Bone Infection With Bacteriophages and Antibiotics Combination. Clin Infect Dis 2019;69:2015-8.

Nouraldin AAM, Baddour MM, Harfoush RAH et al. Bacteriophage-antibiotic synergism to control planktonic and biofilm producing clinical isolates of Pseudomonas aeruginosa. Alexandria J Med 2016;52:99-105.

Oechslin F, Piccardi P, Mancini S et al. Synergistic interaction between phage therapy and antibiotics clears Pseudomonas aeruginosa infection in endocarditis and reduces virulence. $J$ Infect Dis 2016:jiw632.

Oechslin F. Resistance development to bacteriophages occurring during bacteriophage therapy. Viruses 2018;10:351.

Oliveira A, Ribeiro HG, Silva AC et al. Synergistic antimicrobial interaction between honey and phage against Escherichia coli biofilms. Front Microbiol 2017;8:2407.

Oliveira A, Sereno R, Azeredo J. In vivo efficiency evaluation of a phage cocktail in controlling severe colibacillosis in confined conditions and experimental poultry houses. Vet Microbiol 2010;146:303-8.

Ooi ML, Drilling AJ, Morales S et al. Safety and tolerability of bacteriophage therapy for chronic rhinosinusitis due to Staphylococcus aureus. JAMA Otolaryngol - Head Neck Surg 2019;145: 723-9.

Otero J, García-Rodríguez A, Cano-Sarabia M et al. Biodistribution of Liposome-Encapsulated Bacteriophages and Their 
Transcytosis During Oral Phage Therapy. Front Microbiol 2019;10:689.

Parfitt T. Georgia: an unlikely stronghold for bacteriophage therapy. Lancet 2005;365:2166-7.

Park JY, Moon BY, Park JW et al. Genetic engineering of a temperate phage-based delivery system for CRISPR/Cas9 antimicrobials against Staphylococcus aureus. Sci Rep 2017;7:44929.

Parracho HM, Burrowes BH, Enright MC. The role of regulated clinical trials in the development of bacteriophage therapeutics. J Mol Genet Med 2012;06:279-86.

Parsek MR, Greenberg EP. Sociomicrobiology: The connections between quorum sensing and biofilms. Trends Microbiol 2005;13:27-33.

Patterson AG, Jackson SA, Taylor C et al. Quorum Sensing Controls Adaptive Immunity through the Regulation of Multiple CRISPR-Cas Systems. Mol Cell 2016;64:1102-8.

Pearl S, Gabay C, Kishony R et al. Nongenetic individuality in the host-phage interaction. PLoS Biol 2008;6:0957-64.

Pei R, Lamas-Samanamud GR. Inhibition of biofilm formation by T7 bacteriophages producing quorum-quenching enzymes. Appl Environ Microbiol 2014;80:5340-8.

Pelfrene E, Sebris Z, Cavaleri M. Developing Phages into Medicines for Europe. Phage Therapy: A Practical Approach, Switzerland AG: Springer International Publishing, 2019, 351-61.

Pelfrene E, Willebrand E, Cavaleiro Sanches A et al. Bacteriophage therapy: a regulatory perspective. J Antimicrob Chemother 2016;71:2071-4.

Phagothérapie. ANSM - Agence nationale de sécurité du médicament et des produits de santé. Comité scientifique spécialisé temporaire: Phagothérapie. 2016. http://ansm.san te.fr/content/download/91159/1144681/version/1/file/CR_C SST_Phagotherapie_CSST201611013_24-03-2016.pdf.

Pires D, Melo L, Vilas Boas D et al. Phage therapy as an alternative or complementary strategy to prevent and control biofilmrelated infections. Curr Opin Microbiol 2017a;39:48-56.

Pires DP, Cleto S, Sillankorva S et al. Genetically engineered phages: a review of advances over the last decade. Microbiol Mol Biol Rev 2016;80:523-43.

Pires DP, Dötsch A, Anderson EM et al. A genotypic analysis of five $P$. aeruginosa strains after biofilm infection by phages targeting different cell surface receptors. Front Microbiol 2017b;8:1229.

Pirnay J-P, De Vos D, Verbeken G et al. The phage therapy paradigm: prêt-à-porter or sur-mesure? Pharm Res 2011;28:934-7.

Pirnay JP, Blasdel BG, Bretaudeau L et al. Quality and safety requirements for sustainable phage therapy products. Pharm Res 2015;32:2173-9.

Pirnay JP, Verbeken G, Ceyssens PJ et al. The magistral phage. Viruses 2018;10:64.

Rahman M, Kim S, Kim SM et al. Characterization of induced Staphylococcus aureus bacteriophage SAP-26 and its antibiofilm activity with rifampicin. Biofouling 2011;27:1087-93.

Rajnovic D, Muñoz-Berbel X, Mas J. Fast phage detection and quantification: An optical density-based approach. PLoS One 2019;14:e0216292.

Regulation (EU) No 536 /2014. Regulation (EU) No 536/2014 of the European Parliament and of the Council of 16 April 2014 on clinical trials on medicinal products for human use, and repealing Directive 2001/20/EC (2014) Official Journal L158, p. 1-76. 2014.

Regulski K, Champion-Arnaud P, Gabard J. Bacteriophage manufacturing: from early twentieth-century processes to current
GMP. Bacteriophages, Switzerland AG: Springer International Publishing, 2018, 1-31.

Reindel R, Fiore CR. Phage therapy: considerations and challenges for development. Clin Infect Dis 2017;64:1589-90.

Reyes-Robles T, Dillard RS, Cairns LS et al. Vibrio cholerae outer membrane vesicles inhibit bacteriophage infection.J Bacteriol 2018;200:e00792-17.

Rhoads DD, Wolcott RD, Kuskowski MA et al. Bacteriophage therapy of venous leg ulcers in humans: results of a phase I safety trial. J Wound Care 2009;18:237-8, 240-3.

Rogóż P, Amanatullah DF, Międzybrodzki R et al. Phage Therapy in Orthopaedic Implant-Associated Infections. Phage Therapy: A Practical Approach, Switzerland AG: Springer International Publishing, 2019, 189-211.

Rohde C, Wittmann J, Kutter E. Bacteriophages: A therapy concept against multi-drug-resistant bacteria. Surg Infect 2018;19:737-44.

Russian Pharmacopoeia OFS.1.7.1.0002.15, Bacteriophages are therapeutic and prophylactic. 2020. http://pharmacopoeia. ru/ofs-1-7-1-0002-15-bakteriofagi-lechebno-profilaktiches kie/.

Sacher J. Phage banks around the world. Capsid Tail 2019;28.

Samson JE, Magadán AH, Sabri M et al. Revenge of the phages: defeating bacterial defences. Nat Rev Microbiol 2013;11: 675-87.

Sarhan WA, Azzazy HME. Phage approved in food, why not as a therapeutic? Expert Rev Anti Infect Ther 2015;13:91-101.

Sarker SA, Sultana S, Reuteler G et al. Oral Phage Therapy of Acute Bacterial Diarrhea With Two Coliphage Preparations: A Randomized Trial in Children From Bangladesh. EBioMedicine 2016;4:124-37.

Satter SM, Gastanaduy PA, Islam K et al. Hospital-based surveillance for rotavirus gastroenteritis among young children in Bangladesh: Defining the potential impact of a rotavirus vaccine program. Pediatr Infect Dis J 2017;36: 168-72.

Scanlan PD, Buckling A. Co-evolution with lytic phage selects for the mucoid phenotype of Pseudomonas fluorescens SBW25. ISME J 2012;6:1148-58.

Schmerer M, Molineux IJ, Bull JJ. Synergy as a rationale for phage therapy using phage cocktails. PeerJ 2014;2014:e590.

Schooley RT, Biswas B, Gill JJ et al. Development and use of personalized bacteriophage-based therapeutic cocktails to treat a patient with a disseminated resistant Acinetobacter baumannii infection. Antimicrob Agents Chemother 2017;61: e00954-17.

Seviour T, Derlon N, Dueholm MS et al. Extracellular polymeric substances of biofilms: suffering from an identity crisis. Water Res 2019;151:1-7.

Sillankorva S, Neubauer P, Azeredo J. Phage control of dual species biofilms of Pseudomonas fluorescens and Staphylococcus lentus. Biofouling 2010;26:567-75.

Silpe JE, Bassler BL. A host-produced quorum-sensing autoinducer controls a phage lysis-lysogeny decision. Cell 2019;176:268-80 e13.

Stanek JE, Falkinham JO. Rapid coliphage detection assay. J Virol Methods 2001;91:93-8.

Stewart PS, Costerton J. Antibiotic resistance of bacteria in biofilms. Lancet 2001;358:135-8.

Strathdee SA, Patterson TL, Barker T. The Perfect Predator : A Scientist's Race to Save Her Husband from a Deadly Superbug, New York: Hachette Book Group, 2019.

Sulakvelidze A, Alavidze Z, Morris JG. Bacteriophage therapy. Antimicrob Agents Chemother 2001;45:649-59. 
Sumrall ET, Shen Y, Keller AP et al. Phage resistance at the cost of virulence: Listeria monocytogenes serovar $4 \mathrm{~b}$ requires galactosylated teichoic acids for InlB-mediated invasion. Kline KA (ed.). PLoS Pathog 2019;15:e1008032.

Sybesma W, Rohde C, Bardy P et al. Silk route to the acceptance and re-implementation of bacteriophage therapy-Part II. Antibiotics 2018;7:35.

Tagliaferri TL, Jansen M, Horz HP. Fighting pathogenic bacteria on two fronts: phages and antibiotics as combined strategy. Front Cell Infect Microbiol 2019;9:22.

Tait K, Skillman LC, Sutherland IW. The efficacy of bacteriophage as a method of biofilm eradication. Biofouling 2002;18: 305-11.

Tan D, Dahl A, Middelboe M. Vibriophages differentially influence biofilm formation by Vibrio anguillarum strains. Appl Environ Microbiol 2015;81:4489-97.

Tan D, Svenningsen S Lo, Middelboe M. Quorum Sensing Determines the Choice of Antiphage Defense Strategy in Vibrio anguillarum. MBio 2015;6:e00627.

Taylor BP, Penington CJ, Weitz JS. Emergence of increased frequency and severity of multiple infections by viruses due to spatial clustering of hosts. Phys Biol 2017;13:066014.

Testa S, Berger S, Piccardi P et al. Spatial structure affects phage efficacy in infecting dual-strain biofilms of Pseudomonas aeruginosa. Commun Biol 2019;2:1-12.

Tkhilaishvili T, Lombardi L, Klatt AB et al. Bacteriophage Sb1 enhances antibiotic activity against biofilm, degrades exopolysaccharide matrix and targets persisters of Staphylococcus aureus. Int J Antimicrob Agents 2018;52:842-53.

Torres-Barceló C, Hochberg ME. Evolutionary Rationale for Phages as Complements of Antibiotics. Trends Microbiol 2016;24:249-56.

Vinner GK, Richards K, Leppanen M et al. Microencapsulation of enteric bacteriophages in a $\mathrm{pH}$-Responsive solid oral dosage formulation using a scalable membrane emulsification process. Pharmaceutics 2019;11:475.

WHO. Antimicrobial Resistance: Global Report on Surveillance, Switzerland. World Health Organization, 2014, https://www. who.int/drugresistance/documents/surveillancereport/en/.
Withey S, Cartmell E, Avery LM et al. Bacteriophages - Potential for application in wastewater treatment processes. Sci Total Environ 2005;339:1-18.

Woo J, Ahn J. Assessment of synergistic combination potential of probiotic and bacteriophage against antibiotic-resistant Staphylococcus aureus exposed to simulated intestinal conditions. Arch Microbiol 2014;196:719-27.

Wright A, Hawkins CH, Anggård EE et al. A controlled clinical trial of a therapeutic bacteriophage preparation in chronic otitis due to antibiotic-resistant Pseudomonas aeruginosa; a preliminary report of efficacy. Clin Otolaryngol 2009;34:349-57.

Yazdi M, Bouzari M, Ghaemi EA. Isolation and characterization of a lytic bacteriophage (vB-PmiS-TH) and its application in combination with ampicillin against planktonic and biofilm forms of Proteus mirabilis isolated from urinary tract infection. J Mol Microbiol Biotechnol 2018;28:37-46.

Yoichi M, Abe M, Miyanaga $\mathrm{K}$ et al. Alteration of tail fiber protein gp38 enables T2 phage to infect Escherichia coli O157:H7. J Biotechnol 2005;115:101-7.

Yongsheng M, Pacan JC, Wang Q et al. Microencapsulation of bacteriophage felixO1 into chitosan-alginate microspheres for oral delivery. Appl Environ Microbiol 2008;74:4799-805.

Yosef I, Manor M, Kiro R et al. Temperate and lytic bacteriophages programmed to sensitize and kill antibiotic-resistant bacteria. Proc Natl Acad Sci USA 2015;112:7267-72.

Zhang H, Fouts DE, DePew J et al. Genetic modifications to temperate Enterococcus faecalis phage $\varphi$ Ef11 that abolish the establishment of lysogeny and sensitivity to repressor, and increase host range and productivity of lytic infection. Microbiol 2013;159:1023-35.

Zhang Y, Hu Z. Combined treatment of Pseudomonas aeruginosa biofilms with bacteriophages and chlorine. Biotechnol Bioeng 2013;110:286-95.

Zhvania P, Hoyle NS, Nadareishvili L et al. Phage therapy in a 16year-old boy with netherton syndrome. Front Med 2017;4:94.

Zoonotic Diseases | One Health | CDC. CDC - Centers for Disease Control and Prevention. One Health: Zoonotic Diseases. 2017. https://www.cdc.gov/onehealth/basics/zoonoti c-diseases.html. 